\title{
Sensitivity of Sympathetically Correlated Spinal Interneurons, Renal Sympathetic Nerve Activity, and Arterial Pressure to Somatic and Visceral Stimuli after Chronic Spinal Injury
}

\author{
ANDREI V. KRASSIOUKOV, ${ }^{1}$ DEVIN G. JOHNS, ${ }^{2}$ and LAWRENCE P. SCHRAMM ${ }^{2}$
}

\begin{abstract}
In the chronic stage of spinal cord injury in humans, both innocuous and noxious somatic and visceral stimuli can elicit severe autonomic dysreflexia characterized by potentially dangerous, sympathetically mediated, increases in arterial pressure. We hypothesized that a similar sympathetic hyperexcitability would be manifested in spinal sympathetic networks of chronically spinally transected rats. To test this hypothesis, we compared the responses of sympathetically correlated spinal interneurons and arterial pressure to both innocuous and noxious stimuli in acutely and chronically spinally transected rats. Experiments were conducted in anesthetized female rats, either within hours of $T_{3}$ spinal transection (rats with acute spinal transection) or one month after $\mathbf{T}_{3}$ spinal transection (rats with chronic spinal transection). Sympathetically correlated spinal interneurons were identified by cross correlating their ongoing activity with simultaneously recorded renal sympathetic nerve activity. Cutaneous stimuli (either light brushing or noxious pinch) were delivered to a wide area of the ipsilateral side of the rat. Colorectal distension was used as a noxious visceral stimulus. The activity of sympathetically correlated interneurons was increased by stimulation of more of the body surface and decreased by stimulation of less of the body surface in rats with chronic spinal transection than in rats with acute spinal transection. Colorectal distension elicited greater increases in arterial pressure in chronically than acutely spinally-transected rats without exciting significantly more interneurons in those rats. These results suggest that spinal circuits undergo significant plastic changes in the chronic stage of spinal cord injury, and they provide a mechanism for the observation, in some human patients, that many stimuli, both noxious and non-noxious, applied caudal to the site of spinal injury increase sympathetic activity and arterial pressure.
\end{abstract}

Key words: autonomic dysreflexia; hypertensive crises; spinal cord injury; sympathetic activity; sympathetically correlated interneurons

\section{INTRODUCTION}

$\mathbf{T}$ HE ACTIVITY of spinal sympathetic neurons depends upon tonic activation by descending input from supraspinal structures (Alexander, 1946; Calaresu and
Yardley, 1988). Spinal cord injury disrupts these pathways, leaving spinal circuits solely responsible for the generation of sympathetic activity (Maiorov et al., 1997; Osborn et al., 1989). Cardiovascular abnormalities after spinal injury have been well documented in human stud-

\footnotetext{
${ }^{1}$ Division of Neurosurgery, Toronto Western Hospital, University of Toronto, Toronto, Ontario, Canada.

${ }^{2}$ Departments of Biomedical Engineering and Neuroscience, The Johns Hopkins University School of Medicine, Baltimore, Maryland.
} 
ies as well as in animal models (Krassioukov and Weaver, 1995; Maiorov et al., 1998; Maiorov et al. 2001; Mathias and Frankel, 1992; Osborn et al., 1990; Teasell et al., 2000; Karlsson et al., 1998). The initial period after spinal injury is characterized by low arterial blood pressure and persistent bradycardia (Lehmann et al., 1987; Mathias and Frankel, 1992). However, with time, arterial blood pressure becomes volatile, and in some patients it is characterized by episodes of extreme hypertension, manifested by pounding headache, baroreceptor-mediated vagal bradycardia, and upper body flushing. In this condition—autonomic dysreflexia—normally mild stimuli such as cutaneous touch or pressure or distension of the urinary bladder or bowel result in a dramatic elevation in arterial blood pressure that may lead to intracranial hemorrhage and stroke (Mathias and Frankel, 1992; Teasell, et al., 2000). This life-threatening condition is poorly understood despite its high incidence $(\sim 90 \%)$ in people with cervical or high thoracic spinal injury (Braddom and Rocco, 1991; Erickson, 1980; Kewalramani, 1980; Lee et al., 1994). The underlying mechanism for these abnormal responses after chronic spinal injury appears to be an exaggerated response of sympathetic preganglionic neurons to afferent inputs (Mathias and Frankel, 1992; Karlsson et al., 1997). However, it is not clear to what extent spinal interneuronal circuits might also be affected.

In acutely spinally transected rats, Chau et al. (1997, 2000) discovered a population of interneurons in the spinal dorsal horn and intermediate zone that may be important mediators of excitatory input to renal sympathetic preganglionic neurons. The ongoing and stimulus-evoked activities of these neurons are strongly correlated with ongoing and stimulus-evoked changes in renal sympathetic nerve activity (RSNA). These interneurons were further characterized by Miller et al. (2001). The present study tested the hypothesis that these interneurons manifest changes in excitability after spinal injury and that these changes are correlated with altered, stimulusevoked responses in arterial blood pressure.

Although cutaneous stimulation in and near the $T_{10}$ dermatome in acutely spinally transected rats usually increases the discharge rate of $\mathrm{T}_{10}$, sympathetically correlated interneurons, stimulation of regions distal from the $\mathrm{T}_{10}$ dermatome more often decreases the discharge rate of these interneurons. One measure of excitability, therefore, was the incidence of interneurons that were excited or inhibited by cutaneous stimulation of a wide range of regions. We hypothesized that more $\mathrm{T}_{10}$ sympathetically correlated interneurons would be excited and fewer interneurons would be inhibited by stimulation of dermatomes distal from $\mathrm{T}_{10}$ in chronically than in acutely spinally transected rats.
A second measure of sympathetic excitability was the response of $\mathrm{T}_{10}$ sympathetically correlated interneurons to colorectal distension. We hypothesized that colorectal distension would, like cutaneous stimulation, excite a larger percentage of $\mathrm{T}_{10}$ sympathetically correlated interneurons after chronic than after acute spinal transection. A third measure of sympathetic excitability was the effect of colorectal distension on arterial pressure. We hypothesized that if sympathetically correlated interneurons in many thoracic segments (not just $\mathrm{T}_{10}$ ) were excited more by colorectal distension in chronically spinally transected rats, then arterial pressure might rise more in response to this stimulus than in acutely spinally transected rats.

\section{MATERIALS AND METHODS}

The Animal Care and Use Committee of The Johns Hopkins University School of Medicine approved the experimental protocol for these studies. Experiments were conducted in eight acutely spinally transected and 10 chronically spinally transected female Wistar rats (Harlan, 150-180 g). Female rats were used because it was easier to express urine from their bladders than from the bladders of male rats during the early post-transection period. Acute electrophysiological experiments were conducted on anesthetized, acutely spinally transected rats within hours of $T_{3}$ spinal transection and on chronically spinally transected rats at 1 month after transection. Anesthesia was induced by inhalation of halothane (Halocarbon Laboratories, River Edge, NJ; induction 5\%, maintenance during venous cannulation 1-2\%) and continued by alpha-chloralose (100 mg/kg iv; Sigma, St. Louis, MO) delivered via the right femoral vein. The level of anesthesia was monitored, and supplemental doses $(25 \mathrm{mg} / \mathrm{kg})$ were administered as necessary. The trachea was cannulated for artificial ventilation with $100 \%$ oxygen. Rats were placed in a stereotaxic frame and paralyzed with galamine triethiodide (initial dose $40 \mathrm{mg} / \mathrm{kg}$ iv, Sigma). Body temperature was monitored and maintained at $37^{\circ} \mathrm{C}$ with a heating pad. The right femoral artery was cannulated to measure arterial blood pressure. Rats were shaved, and the left side was marked with a reference grid for mapping responses to cutaneous stimulation (Fig. 1, upper panel) as described previously (Chau et al., 1997).

\section{Chronic Spinal Cord Transection and Rat Care}

In chronically spinally transected rats, the third thoracic segment was exposed by a dorsal laminectomy. Under halothane anesthesia (see above), the dura was opened, and the cord was transected. Completeness of cord transection was verified, and the wound was closed. Rats recovered in temperature-controlled cages and were 

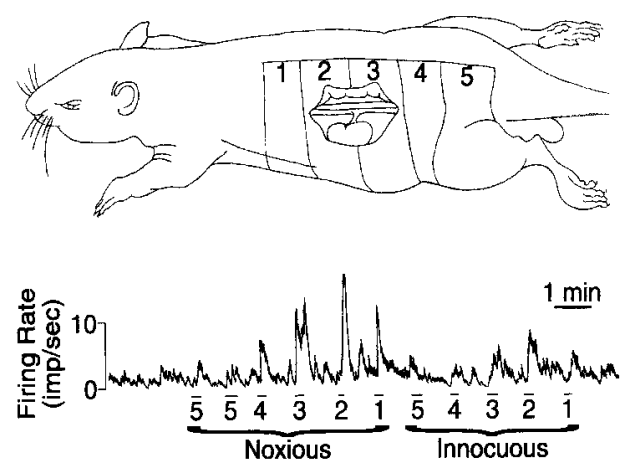

FIG. 1. (Upper panel). Schematic drawing of the cutaneous regions from which responses of spinal sympathetically correlated interneurons were elicited. (Lower panel). Representative rate meter responses of a sympathetically correlated neuron to noxious (left) and innocuous (right) stimulation of cutaneous regions 1-5 (lower panel).

treated with a dose of antibiotic (Penloge-S, 20,000 IU, intramuscularly) and analgesic (Banamine, $1.1 \mathrm{mg} / \mathrm{kg} \mathrm{sc}$; Schering-Plough Animal Health, Kenilworth, NJ). Lactated Ringer's solution ( $5 \mathrm{~mL} \mathrm{sc}$ ) was also given immediately after surgery to provide hydration for the first few hours of recovery. All rats had convenient access to water and standard laboratory chow. Rats were kept in a temperature- and light-controlled room. The first dark period of a 24-h light/dark cycle was inaugurated at 20:00 $\mathrm{h}$ after spinal cord transection. The urinary bladder was emptied by manual compression four times daily for the first 3-7 days after surgery. Gradually, all rats began voiding spontaneously, and manual expression was terminated. Detailed protocols for the care of rats after spinal cord transection have been described previously (Krassioukov and Weaver, 1996; Osborn et al., 1989).

\section{Colorectal Distension}

A latex balloon-tipped catheter (10-mm-long, SwanGanz, 7 French; Baxter, Deerfield, IL) was inserted through the anus $1.5 \mathrm{~cm}$ into the colon. The catheter was fixed to the tail with adhesive tape. Colorectal distension was produced by inflation of the balloon with $2 \mathrm{~mL}$ of air for one min as described previously (Krassioukov and Weaver, 1995). The balloon exerted a pressure of approximately $35 \mathrm{~mm} \mathrm{Hg}$, as measured through a side arm of the catheter. Changes in all rats of the activity of sympathetically correlated spinal interneurons and mean arterial pressure in response to colorectal distension were recorded digitally on magnetic tape.

\section{Cutaneous Stimulation}

Two somatic stimuli were used to assess inputs affecting the spinal interneurons, an innocuous light touch with a cotton applicator and a noxious pinch with toothed forceps maintained for $10 \mathrm{sec}$. A response was considered excitatory or inhibitory if spinal neuronal activity increased or decreased $>10 \%$ from the pre-stimulus level. During recordings of most interneurons, both innocuous and noxious stimuli were applied systematically to the five somatic regions outlined in the upper panel of Figure 1.

\section{Assessment of Responses to Somatic Stimuli}

Responses to somatic stimuli were analyzed in two ways to determine differences in the incidence of interneurons either excited or inhibited by innocuous or noxious cutaneous stimulation in rats with acute and chronic spinal transections. In the first case (Table 1), the incidence of sympathetically correlated interneurons that were and were not excited in rats with acute spinal cord transections were compared with the incidence of sympathetically correlated interneurons that were and were not excited in rats with chronic spinal transections using $2 \times 2$ contingency tables. In the second case (Table 2 ), the numbers of sympathetically correlated interneurons that were and were not inhibited were similarly compared.

\section{Electrophysiological Recordings}

Details of these methods have been described elsewhere (Chau et al., 1997). We recorded RSNA in the left renal nerve using bipolar electrodes connected to a differential amplifier with a bandpass of 300-3,000 Hz. Sympathetic activity was further processed by rectification and lowpass filtering at a time constant of $0.1 \mathrm{sec}$. Extracellular recordings of the activity of spinal interneurons at $\mathrm{T}_{10}$ were made with single-barrel, carbon-fiber microelectrodes (impedance 2-4 M $)$ ). This signal was amplified, filtered (300-3,000-Hz bandpass) and recorded on magnetic tape with simultaneously recorded RSNA and arterial blood pressure. The action potentials of individual interneurons were detected with a dual window discriminator (Bak Electronics, Mt. Airy, MD). To avoid recording from sympathetic preganglionic neurons, we studied only neurons that exhibited interspike intervals shorter than those observed in preganglionic neurons $(<50 \mathrm{msec})$. We measured the responses of sympathetically correlated interneurons to innocuous and noxious cutaneous stimulation by delivering stimuli to defined regions on the ipsilateral body wall (upper panel, Fig. 1). We measured the responses to colorectal distension of the activity of sympathetically correlated interneurons, and we measured the responses of arterial blood pressure to colorectal distension.

The present experiments on acutely spinally transected rats were similar to those conducted previously in this laboratory with respect to their duration and the degree of dif- 
Table 1. Numbers and Percentages of Neurons Excited and Not Excited by Noxious and Innocuous Cutaneous Stimulation in Rats with Acute and Chronic Spinal Transections

\begin{tabular}{|c|c|c|c|c|c|}
\hline \multirow[b]{2}{*}{ Region } & \multirow[b]{2}{*}{ Transection } & \multicolumn{2}{|c|}{ Innocuous stimuli } & \multicolumn{2}{|c|}{ Noxious stimuli } \\
\hline & & Neurons excited & Neurons not excited & Neurons excited & Neurons not excited \\
\hline \multirow[t]{2}{*}{1} & Acute & $3(11 \%)$ & $24(89 \%)$ & $9(33 \%)$ & $18(67 \%)$ \\
\hline & Chronic & $13(59 \%)^{* * \prime}$ & $9(41 \%)$ & $15(68 \%)^{*}$ & $7(32 \%)$ \\
\hline \multirow{2}{*}{2} & Acute & $12(44 \%)$ & $15(56 \%)$ & $17(63 \%)$ & $10(37 \%)$ \\
\hline & Chronic & $12(55 \%)$ & $10(45 \%)$ & $17(77 \%)$ & $5(23 \%)$ \\
\hline \multirow[t]{2}{*}{3} & Acute & $3(11 \%)$ & $24(89 \%)$ & $7(25 \%)$ & $21(75 \%)$ \\
\hline & Chronic & $11(50 \%)^{* * \prime}$ & $11(50 \%)$ & $16(73 \%)^{* *}$ & $6(27 \%)$ \\
\hline \multirow[t]{2}{*}{4} & Acute & $3(11 \%)$ & $24(89 \%)$ & $5(18 \%)$ & $23(82 \%)$ \\
\hline & Chronic & $5(23 \%)$ & $17(77 \%)$ & $7(32 \%)$ & $15(68 \%)$ \\
\hline \multirow[t]{2}{*}{5} & Acute & $1(4 \%)$ & $26(96 \%)$ & $3(11 \%)$ & $25(89 \%)$ \\
\hline & Chronic & $6(29 \%)^{* \prime}$ & $15(71 \%)$ & $10(48 \%)^{* *}$ & $11(52 \%)$ \\
\hline
\end{tabular}

$* * p<0.01$, significantly more neurons were excited in acutely transected rats than in chronically transected rats.

$* *^{\prime} p<0.01$, significantly more neurons were excited in acutely transected rats than in chronically transected rats, but number of neurons in one category was $<6$.

${ }^{*} p<0.05$, significantly more neurons were excited in acutely transected rats than in chronically transected rats.

$*^{\prime} p<0.05$, significantly more neurons were excited in acutely transected rats than in chronically transected rats, but number of neurons in one category was $<6$.

ficulty of recording from interneurons while conducting cutaneous and visceral stimulation. The experiments on chronically spinally transected rats, however, were somewhat more difficult. Although these rats appeared to be in good health, they were less likely to survive long experiments than were the acutely transected rats. Further, vertebral distortions caused by the chronic laminectomy decreased our ability to firmly stabilize the spinal cord, resulting in premature loss of interneurons during mechanical stimulation. In several instances, responses of neurons to cutaneous stimulation could not be obtained for all five cutaneous regions. Therefore, the total number of neurons entered in Tables 1 and 2 for some regions are smaller than the total number of neurons recorded in rats with acute or chronic spinal cord transections.

\section{Correlation of the Activity of Spinal Interneurons with RSNA}

Ongoing RSNA and the ongoing activity of spinal interneurons were recorded for periods of at least $10 \mathrm{~min}$. The occurrence of discharges of interneurons was crosscorrelated with ongoing RSNA during this period (Fig. 2,

Table 2. Numbers and Percentages of Neurons Inhibited and Not Inhibited by Noxious and Innocuous Cutaneous Stimulation in Rats with Acute and Chronic Spinal Transections

\begin{tabular}{|c|c|c|c|c|c|}
\hline \multirow[b]{2}{*}{ Region } & \multirow[b]{2}{*}{ Transection } & \multicolumn{2}{|c|}{ Innocuous stimuli } & \multicolumn{2}{|c|}{ Noxious stimuli } \\
\hline & & Neurons inhibited & Neurons not inhibited & Neurons inhibited & Neurons not inhibited \\
\hline \multirow[t]{2}{*}{1} & Acute & $10(37 \%)$ & $17(63 \%)$ & $6(22 \%)$ & $21(78 \%)$ \\
\hline & Chronic & $1(5 \%)^{* \prime}$ & $21(95 \%)$ & $6(27 \%)$ & $16(73 \%)$ \\
\hline \multirow[t]{2}{*}{2} & Acute & $5(19 \%)$ & $22(81 \%)$ & $3(11 \%)$ & $24(89 \%)$ \\
\hline & Chronic & $1(5 \%)$ & $21(95 \%)$ & $4(18 \%)$ & $18(82 \%)$ \\
\hline \multirow[t]{2}{*}{3} & Acute & $6(22 \%)$ & $21(73 \%)$ & $3(11 \%)$ & $25(89 \%)$ \\
\hline & Chronic & $1(5 \%)$ & $21(95 \%)$ & $2(9 \%)$ & $20(91 \%)$ \\
\hline \multirow[t]{2}{*}{4} & Acute & $9(33 \%)$ & $18(67 \%)$ & $12(43 \%)$ & $16(57 \%)$ \\
\hline & Chronic & $4(18 \%)$ & $18(82 \%)$ & $9(41 \%)$ & $13(59 \%)$ \\
\hline \multirow[t]{2}{*}{5} & Acute & $12(44 \%)$ & $15(56 \%)$ & $17(61 \%)$ & $11(39 \%)$ \\
\hline & Chronic & $3(14)^{* \prime}$ & $18(86 \%)$ & $7(33 \%)$ & $14(67 \%)$ \\
\hline
\end{tabular}

${ }^{*} p<0.05$, significantly more neurons were inhibited in acutely transected rats than in chronically transected rats, but number of neurons in one category was $<6$. 

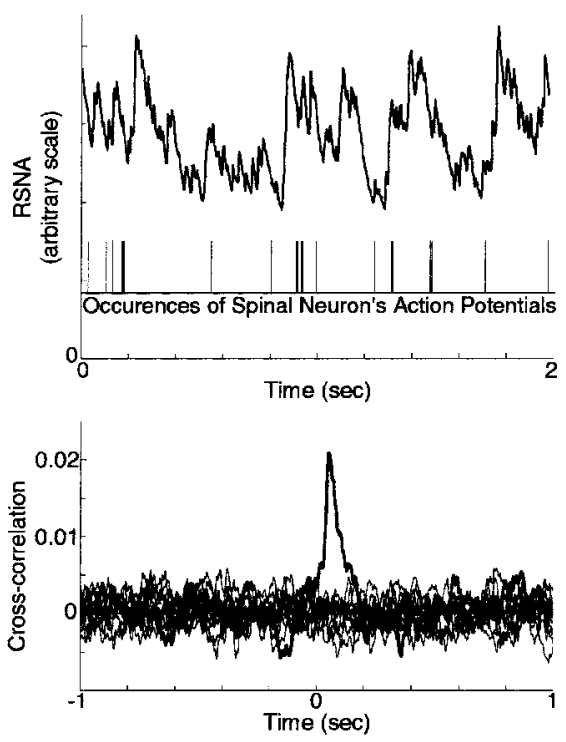

FIG. 2. (Upper panel). Renal sympathetic nerve activity (RSNA, upper trace) and simultaneously recorded occurrences of action potentials in a sympathetically correlated spinal interneuron (lower trace). (Lower panel). Cross correlation of 10 min of records of spinal neuronal action potentials and renal sympathetic nerve activity. Dark trace is actual cross correlation. Light traces are dummy cross correlations for comparison. Because sympathetic activity in this experiment was positively correlated with spinal neuronal action potentials, the correlogram had a large positive peak approximately $75 \mathrm{msec}$ after the occurrence of action potentials (at time $=0$ ).

lower panel) as described previously (Chau et al., 1997). The rationale for this method was that, if bursts of RSNA were being generated by networks that include the interneurons from which we were recording, then the crosscorrelation between the bursts of RSNA activity and the discharges of the interneurons should have exhibited a significant peak at a latency after the discharge of the interneurons that was consistent with the conduction of the pre- and postganglionic neurons from the spinal cord to the recording electrode on the renal nerve $(<100 \mathrm{msec})$.

The peak magnitudes of the resulting cross-correlations were compared with dummy correlations, generated by cross-correlating RSNA with artificial spike trains using randomized interspike intervals drawn from the recorded data. Neurons were considered correlated with RSNA if the peak values of their cross-correlations (less than 100 msec after the occurrence of spinal neuronal activity) were more than twice the peak values of the dummy correlation (Fig. 2, lower panel).

\section{Histology}

Rats were euthanized with an intravenous overdose of anesthetic and perfused transcardially with $500 \mathrm{~mL}$ of 0.1
M phosphate-buffered saline followed by $500 \mathrm{~mL}$ of $4 \%$ buffered formaldehyde. Spinal cords were removed and post-fixed for $24 \mathrm{hr}$, then cryoprotected in sucroseformaldehyde solution $(30 \%$ sucrose in $4 \%$ buffered formaldehyde, $\mathrm{pH} 7.4$ ) for $2-5$ days. Thirty-five- $\mu \mathrm{m}$ horizontal sections of the $\mathrm{T}_{2-3}$ segments from chronically spinally transected rats were cut with a cryostat and thawmounted onto gelatin-coated slides to verify that transection was complete. Approximate rostrocaudual and mediolateral recording sites were determined from the entry site of the electrode. Approximate recording depths were determined from the digital readout on the microelectrode drive.

\section{Statistical Analysis}

All arterial pressures and changes in arterial pressures are presented as means \pm 1 standard error of the mean. Differences between means were computed using a $t$ test (Snedecor and Cochran, 1989). Values of $p<0.05$ were considered significant.

Differences in the incidence of interneurons excited and inhibited by cutaneous stimulation of regions on the body wall in rats with acute and chronic spinal transections were studied using $2 \times 2$ contingency tables. Fisher's exact test (Snedecor and Cochran, 1989) was used to test the significance of differences observed in contingency tables. We were unable to divide interneurons into three response categories-excited, no response, and inhibited - because our small sample size resulted in a substantial number of categories with no entries. This condition rendered the calculation of contingency tables invalid. Therefore, we combined categories and compared in rats with acute and chronic spinal transections the incidence of excited interneurons by classifying interneurons as either excited or not excited (the "not excited" category including both non-responding interneurons and inhibited interneurons). Similarly, we compared in rats with acute and chronic spinal transections the incidence of inhibited interneurons by categorizing interneurons as either inhibited or not inhibited (the "not inhibited category including both non-responding interneurons and excited interneurons).

\section{RESULTS}

\section{Sympathetically Correlated Spinal Interneurons in Acutely Spinally Transected Rats}

Only positively correlated interneurons located in the $\mathrm{T}_{10}$ spinal segment were studied in these experiments. Responses to both cutaneous stimulation and colorectal distension were obtained from 27 sympathetically corre- 
lated interneurons recorded in rats with acute spinal transections. These interneurons were located $25-1,130 \mu \mathrm{m}$ from the dorsal surface of the spinal cord. In some cases, a temporal relationship could be seen between bursts of activity in sympathetically correlated interneurons and simultaneously recorded RSNA. For example, bursts of RSNA can be seen to follow many (but not all) of an interneuron's action potentials in the upper panel of Figure 2. This relationship was less clear in many recordings. Therefore the relationships between the activity of spinal interneurons and RSNA were always confirmed by cross correlating these variables, as described in METHODS.

Cross correlations provided data such as those shown in the lower panel of Figure 2. The single dark trace is the true cross correlation between an interneuron's impulses and simultaneously recorded RSNA. The duration of these recordings was approximately 300 times the length of the segment shown in the upper panel of Figure 2. The lighter traces in the correlogram indicate a population of 20 dummy correlations between the same recording of RSNA used for the true correlation and trains of artificial action potentials with randomized inter-spike intervals. Thus, the dummy correlations provide a measure of the "noise" in the true cross-correlation, and only interneurons with cross-correlations at least twice the magnitude of the envelope of the dummy averages were considered sympathetically correlated.

The responses to both innocuous and noxious cutaneous stimulation of five regions on the ipsilateral flank and hip (Fig. 1, upper panel) were tested. Typical responses to the two intensities of cutaneous stimulation are shown in the lower panel of Figure 1. Confirming previous studies in this laboratory, in acutely spinally transected rats the largest percentage of interneurons were excited by both innocuous and noxious stimulation of the putative $\mathrm{T}_{10}$ dermatome (region 2, upper panel, Fig. 1).

\section{Sympathetically Correlated Spinal Interneurons in Chronically Spinally Transected Rats}

Twenty-two sympathetically correlated interneurons were recorded in rats with chronic spinal transections. These interneurons were located $30-1,000 \mu \mathrm{m}$ from the dorsal surface of the spinal cord. Innocuous and noxious somatic stimuli were delivered to the same five somatic regions explored in rats with acute spinal transections. Then, we compared the incidence of neurons excited (Table 1) and inhibited (Table 2) in acutely and chronically spinally transected rats (see methods for details of response classification).

Compared to the effects of cutaneous stimulation in rats with acutely transected spinal cords, a significantly larger percentage of interneurons was excited in rats with chronically transected spinal cords by cutaneous stimu- lation in regions 1,3 , and 5 (Table 1). It is especially noteworthy that, in these regions, interneurons were more likely to be excited by both innocuous and noxious stimulation. Further, compared to the effects of cutaneous stimulation in rats with acutely transected spinal cords, a significantly smaller percentage of interneurons was inhibited by innocuous stimulation of regions 1 and 5 (Table 2) in rats with chronically transected spinal cords. No significant differences in the incidence of interneurons inhibited by noxious stimulation was observed for any cutaneous region in rats with acutely and chronically transected spinal cords

\section{Reaction of Mean Arterial Pressure, RSNA, and Sympathetically Correlated Spinal Interneurons to Colorectal Distension}

Resting mean arterial pressures in anesthetized, acutely and chronically spinally transected rats were $60 \pm 3.2$ and $92 \pm 7.5 \mathrm{~mm} \mathrm{Hg}$, respectively $(p<0.002)$. We were able to perform colorectal distension during recordings of 18 interneurons in rats with chronic spinal transections and in 27 interneurons in rats with acute spinal transections. Changes in mean arterial pressure in response to colorectal distension in chronically spinally transected rats were significantly larger $(21.5 \pm 4.5 \mathrm{~mm} \mathrm{Hg})$ than those in acutely spinally transected rats $(6.7 \pm 0.5 \mathrm{~mm}$ $\mathrm{Hg}, p<0.01)$. Colorectal distension increased RSNA in all acutely and chronically spinally-transected rats. We did not observe a statistically significant difference between the incidence of excited $\mathrm{T}_{10}$ sympathetically correlated interneurons in response to colorectal distension rats with acutely and chronically transected spinal cords. Twelve interneurons (43\%) were excited, and 16 interneurons $(57 \%)$ were unaffected by colorectal distension in rats with acutely transected spinal cords. Eleven interneurons $(61 \%)$ were excited, and seven interneurons $(39 \%)$ were unaffected by colorectal distension in rats with chronically transected spinal cord $(p>0.36$, Fisher's exact test). No interneurons were inhibited by colorectal distension in either rats with acute or chronic spinal transections.

\section{DISCUSSION}

The ongoing activities of all of the interneurons reported were strongly positively correlated with ongoing RSNA. In other words, these interneurons' action potentials were often followed by bursts of RSNA. Previous studies in this laboratory have shown that the activities of approximately $30 \%$ of interneurons in the $\mathrm{T}_{10}$ segment exhibit such correlations and that the percentage of sympathetically correlated interneurons diminishes rapidly 
rostral and caudal to this level (Chau et al., 1997, 2000; Miller et al., 2001). We concentrated on sympathetically correlated interneurons in the $T_{10}$ segment because our previous studies have shown that not only their ongoing activities but also their responses to somatic stimuli are strongly correlated to changes in RSNA (Chau at al., 1997, 2000). These observations are consistent with the hypothesis that sympathetically correlated spinal interneurons are candidates for membership in spinal networks responsible for activating sympathetic preganglionic neurons after spinal cord transection. If this is correct, then conditions that increase the number of positively correlated interneurons that are excited by a stimulus and decrease the number of positively correlated interneurons inhibited by a stimulus will, via either mechanism, predispose an animal to a larger sympathetic response to that stimulus. Therefore, based on previous observations of sympathetic hyper-responsiveness after chronic spinal transection (Berkley et al., 1993; Krassioukov and Weaver, 1995; Maiorov et al., 1997), we predicted that sympathetically positively correlated interneurons would be more likely to be excited and less likely to be inhibited by cutaneous and visceral stimuli in chronically spinally-transected rats than would sympathetically correlated interneurons in acutely spinallytransected rats.

The results of this study confirm this prediction for $\mathrm{cu}-$ taneous stimulation of some cutaneous regions but not for colorectal distension. Both innocuous and noxious somatic stimulation of cutaneous regions 1,3 , and 5 excited a larger proportion of sympathetically correlated $\mathrm{T}_{10}$ interneurons in chronically than in acutely spinally-transected rats. Differences in excited interneurons in regions 2 and 4 were not statistically significant. The less striking difference in responses to stimulating region 2 may have occurred because even in rats with acutely transected spinal cords nearly half of the sympathetically correlated interneurons already were excited by innocuous cutaneous stimulation.

The smaller difference in the incidence of excited interneurons in rats with acute and chronic spinal transection in region 4 may have been related to the observation that many sympathetically correlated interneurons are inhibited by stimulation of region 4 in rats with either acutely or chronically transected spinal cords (Chau et al., 1997; Table 1). Although stimulation of region $4 \mathrm{ex}-$ cited almost twice as many interneurons in rats with chronically transected spinal cords than in rats with acutely transected spinal cords, the actual number of excited interneurons was so small that this difference was not significant. Stimulation of region 5 also excited relatively few interneurons. However, the sixfold larger number of interneurons excited by innocuous stimulation and the threefold greater number of interneurons excited by noxious stimulation in rats with chronically transected spinal cords were significantly different.

As predicted, the increased incidence of excited interneurons in rats with chronically transected spinal cords was not due solely to a smaller incidence of interneurons that did not respond to cutaneous stimulation. The incidence of interneurons inhibited by innocuous stimulation of regions 1 and 5 was smaller (Table 2).

Colorectal distension did not excite significantly more interneurons recorded in rats with acute spinal transections than in rats with chronic spinal transections. As discussed in detail by Chau, et al. (2000), responses of $\mathrm{T}_{10}$ sympathetically correlated interneurons to colorectal distension are difficult to predict. Unlike $\mathrm{T}_{10}$ interneurons' responses to distal cutaneous stimulation (which are more likely to be inhibitory), their responses to colorectal stimulation are frequently excitatory. This observation was confirmed in the present study, in which relatively few interneurons were excited by either innocuous or noxious cutaneous stimulation of regions 4 and 5 in rats with acute spinal transections (Table 1), but $43 \%$ were excited by colorectal distension in the same acutely transected preparations. Thus, rats with chronically transected spinal cords would have had to exhibit a very large incidence (approaching 100\%) of neurons excited by colorectal distension for the difference between rats with acute and chronic spinal transections to be significant.

Given the failure of chronic spinal transection to elevate the incidence of excited $T_{10}$ interneurons significantly, how can we account for the observation that colorectal distension elicited larger increases in arterial pressure in rats with chronic spinal transections than in rats with acute spinal transections? The most likely explanation is that a larger percentage of interneurons at levels other than $\mathrm{T}_{10}$ may have been excited by colorectal distention. We sampled only sympathetically correlated interneurons at $\mathrm{T}_{10}$. Chau et al. (2000) suggested that, in spinally transected rats, the likelihood of interneurons being excited increases with proximity to the segmental input for a stimulus. If this is correct, then colorectal distension could have had even greater effects on sympathetic preganglionic neurons more caudal than $\mathrm{T}_{10}$, neurons that affect, for instance, the vascular resistance of tissues in the lower limbs, lower body wall, and caudal viscera. Even modestly increased effects of colorectal distension on these sympathetic outputs, added to effects on $\mathrm{T}_{10}$ and more rostral sympathetic outputs may have been responsible for the larger increases in arterial pressures observed in rats with chronic spinal transections. Recordings from additional thoracic and lumbar spinal segments would be necessary to test this hypothesis. 
These experiments provide a neurophysiological mechanism for the autonomic dysreflexia seen in patients in the chronic phase of spinal cord injury. In some patients, even innocuous visceral or somatic stimuli caudal to the injury can elicit potentially dangerous increases in arterial pressure, and noxious stimuli affect even more patients (Mathias and Frankel, 1992). We consider it particularly significant that both innocuous and noxious stimuli excited sympathetically correlated interneurons from a wider range of somatic sites after chronic spinal transection and that inhibitory influences from some somatic sites were reduced in these same rats. Thus, elevated spinal sympathetic excitability in this preparation occurs not only to potentially damaging stimuli but to mild stimuli as well, even in the presence of general anesthesia.

Although the present experiments demonstrate a tendency for putative spinal sympathetic systems to be excited by anatomically more distal stimuli and inhibited by more proximal stimuli after chronic spinal transection, they did not address the mechanisms affecting excitability. Therefore, none of the potential mechanisms implicating changes in the anatomy and physiology of the sympathetic preganglionic interneurons, sympathetically correlated precursor interneurons, or primary afferents has been eliminated. Indeed, changes at all of these sites may occur after chronic spinal transection, and changes have already been noted in the morphologies of both sympathetic preganglionic neurons and primary afferents. Previously it was found that, after a brief period of dendritic atrophy in sympathetic preganglionic neurons following chronic spinal transection, dendritic arbors rapidly recovered, parallel to the onset of sympathetic dysreflexia in rats (Krassioukov and Weaver, 1996; Krenz and Weaver, 1998a). Krenz and Weaver (1998b) also showed that chronic spinal cord transection was followed by substantial sprouting and increased putative terminations of CGRP-containing fibers in the dorsal horn and Clarke's column caudal to the lesion. The development of these terminations closely paralleled the onset of increased responses of arterial pressure to afferent stimuli.

In summary, $\mathrm{T}_{10}$ spinal interneurons which are potential members of spinal networks responsible for generating sympathetic activity were excited by stimulation of a larger region of the body wall and inhibited by stimulation of a smaller region of the body wall in rats with chronic spinal transections than were similar interneurons in rats with acute spinal transections. Although significantly more sympathetically correlated $\mathrm{T}_{10}$ spinal interneurons were not excited by colorectal distension in rats with chronic spinal transections, larger increases in arterial pressure were elicited by this stimulus in those rats, possibly mediated by hyperexcitability of neurons in segments other than $T_{10}$. These observations suggest neurophysiological mechanisms for the dysreflexia elicited by even modest pelvic stimulation and stimulation of the lower extremity that is observed after chronic spinal cord injury.

\section{ACKNOWLEDGMENTS}

This research was supported by NIH grant HL16315 to L.P.S. and a grant from The Dean of Utica College of Syracuse University to A.V.K. We gratefully acknowledge the editorial assistance of Diana C. Schramm.

\section{REFERENCES}

ALEXANDER, R.S. (1946). Tonic and reflex functions of medullary sympathetic cardiovascular centers. J. Neurophysiol. 9, 205-217.

BERKLEY, K.J., GUILBAUD, G., BENOIST, J.-M., et al. (1993). Responses on neurons in and near the thalamic ventrobasal complex of the rat to stimulation of uterus, cervix, vagina, colon, and skin. J. Neurophysiol. 69, 557-568.

BRADDOM, R.L., and ROCCO, J.F. (1991). Autonomic dysreflexia: a survey of current treatment. Am. J. Phys. Med. Rehabil. 70, 234-241.

CALARESU, F.R., and YARDLEY, C.P. (1988). Medullary basal sympathetic tone. Ann. Rev. Physiol. 50, 511-524.

CHAU, D., JOHNS, D.G., and SCHRAMM, L.P. (2000). Ongoing and stimulus-evoked activity of sympathetically correlated neurons in the intermediate zone and dorsal horn of acutely spinalized rats. J. Neurophysiol. 83, 2699-2707.

CHAU, D., KIM, N., and SCHRAMM, L.P. (1997). Sympathetically correlated activity of dorsal horn neurons in spinally transected rats. J. Neurophysiol. 77, 2966-2974.

ERICKSON, R.P. (1980). Autonomic hyperreflexia: pathophysiology and medical management. Arch. Phys. Med. Rehabil. 61, 431-440.

KARLSSON, A.K., FRIBERG, P., LONNROTH, P., et al. (1998). Regional sympathetic function in high spinal cord injury during mental stress and autonomic dysreflexia. Brain 121, 1711-1719.

KARLSSON, A.K., ELAM, M., FRIBERG, P., et al., (1997) Peripheral afferent stimulation of decentralized sympathetic neurons activates lipolysis in spinal cord-injured subjects. Metabolism, 46, 1465-9.

KEWALRAMANI, L.S. (1980). Autonomic dysreflexia in traumatic myelopathy. Am. J. Phys. Med. Rehabil. 59, 1-21.

KRASSIOUKOV, A.V., and WEAVER, L.C. (1995). Episodic hypertension due to autonomic dysreflexia in acute and chronic spinal cord-injured rats. Am. J. Physiol. 268, H2077-H2083. 
KRASSIOUKOV, A.V., and WEAVER, L.C. (1996). Morphological changes in sympathetic preganglionic neurons after spinal cord injury in rats. Neuroscience 70, 211-226.

KRENZ, N.R., and WEAVER, L.C. (1998a). Changes in the morphology of sympathetic preganglionic neurons parallel the development of autonomic dysreflexia after spinal cord injury in rats. Neurosci. Lett. 243, 61-64.

KRENZ, N.R., and WEAVER, L.C. (1998b). Sprouting of primary afferent fibers after spinal cord transection in the rat. Neuroscience 85, 443-458.

LEE, B.Y., KARMAKAR, M.G., HERZ, B.L., et al. (1994). Autonomic dysreflexia revisited. J. Spinal Cord Med. 18, 75-87.

LEHMANN, K.G., LANE, J.G., PIEPMEIER, J.M., et al. (1987). Cardiovascular abnormalities accompanying acute spinal cord injury in humans: incidence, time course and severity. J. Am. Coll. Cardiol. 10, 46-52.

MAIOROV, D.N., FEHLINGS, M.G., and KRASSIOUKOV, A.V. (1998). Relationship between severity of spinal cord injury and abnormalities in neurogenic cardiovascular control in conscious rats. J. Neurotraum. 15, 365-374.

MAIOROV, D.N., WEAVER, L.C., and KRASSIOUKOV, A.V. (1997). Relationship between sympathetic activity and arterial pressure in conscious spinal rats. Am. J. Physiol. 272, H625-H631.

MAIOROV, D.N., ADAMS, M.A., and KRASSIOUKOV, A.V. (2001). Telemetric blood pressure monitoring in conscious rats before and after compression injury of the spinal cord. J. Neurotrauma 18, 727-736.

MATHIAS, C.J. and FRANKEL, H.L. (1992). The cardiovas- cular system in tetraplegia and paraplegia, in: Handbook of Clinical Neurology. H.L. Frankel (eds), Elsevier Science Publishers: Amsterdam, pps. 435-456.

MILLER, C.O., JOHNS, D.G., and SCHRAMM, L.P. (2001). Spinal interneurons play a minor role in generating ongoing renal sympathetic nerve activity in spinally intact rats. $\mathrm{Br}$. Res. 918, 101-106.

OSBORN, J.W., TAYLOR, R.F., and SCHRAMM, L.P. (1989). Determinants of arterial pressure after chronic spinal transection in rats. Am. J. Physiol. 256, R666-R673.

OSBORN, J.W., TAYLOR, R.F., and SCHRAMM, L.P. (1990). Chronic cervical spinal cord injury and autonomic hyperreflexia in rats. Am. J. Physiol. 258, R169-R174.

SNEDECOR, G.W., and COCHRAN, W.G. (1967). Statistical Methods. The Iowa State University: Ames, IA.

TEASELL, R., ARNOLD, A.P., KRASSIOUKOV, A.V., et al. (2000). Cardiovascular consequences of loss of supraspinal control of the sympathetic nervous system following spinal cord injuries. Arch. Phys. Med. Rehabil. 81, 506-516.

Address reprint requests to: Lawrence P. Schramm, Ph.D. Departments of Biomedical Engineering and Neuroscience The Johns Hopkins University School of Medicine 720 North Rutland Av. 606 Traylor Bldg. Baltimore, MD 21205-2196

E-mail:1schramm@bme.jhu.edu 